\title{
Implante Valvular Aórtico Percutâneo: Já Podemos Considerar um Procedimento Rotineiro e Incorporá-lo à Prática Médica?
}

Ver artigo relacionado na página 176

\author{
Rogério Sarmento-Leite ${ }^{1}$
}

A estenose valvar aórtica é uma doença de alta prevalência nas faixas etárias mais elevadas. Estima-se que aproximadamente $5 \%$ da população adulta com mais de 75 anos de idade sofra dessa condição ${ }^{1}$. Se considerarmos a progressão prevista para os próximos anos da pirâmide demográfica para a forma de trapézio, pelo aumento da proporção de idosos, a história natural da estenose aórtica degenerativa tende a ganhar ainda mais relevância médico-social ${ }^{2}$. O impacto disso torna-se ainda maior visto que se trata de um fenômeno global e de prognóstico reservado naqueles pacientes cujos sintomas clínicos já estejam se manifestando. Todavia, muitos desses pacientes (até 33\%) são e serão deferidos da cirurgia de substituição valvar ${ }^{3}$, tratamento considerado padrão de referência, por serem caracterizados como de alto risco e com grande potencial de morbidade e mortalidade, seja pela idade seja por outras doenças associadas. Assim, o surgimento de opções menos invasivas para o tratamento desses pacientes torna-se obrigatório e premente.

O implante valvular aórtico percutâneo emerge como uma promissora e muito atraente alternativa. Já existem, inclusive, dois dispositivos comercialmente disponíveis para uso e outros ainda em fase de testes. Seja pela via femoral, subclávia/axiliar ou transapical, o método tem se mostrado exequível, seguro e altamente eficaz para esse subgrupo de pacientes ${ }^{4}$. Isso também já foi demonstrado em nosso meio ${ }^{5}$ e parece estar sendo utilizado com sucesso e em larga escala por vários centros em todo o mundo, o que fica bem evidenciado pela experiência de Hernández-García et al. ${ }^{6}$, publicada nesta edição da Revista Brasileira de Cardiologia Invasiva.

Parece, então, que, de fato, a técnica vem se popularizando e ficando ao alcance da comunidade médico-científica e, sobretudo, daqueles pacientes con- siderados de mais alto risco. Todavia, seu uso ainda é limitado pelo alto custo e pela complexa e prolongada curva de aprendizado, barreiras essas que tendem a diminuir com o surgimento de novos dispositivos, investimentos em treinamento e educação a respeito do método.

No que se refere a novos dispositivos, experimentos estão sendo feitos no intuito de corrigir as limitações dos atualmente disponíveis, em especial no que diz respeito à diminuição do calibre e diâmetro dos sistemas de entrega. São necessários também melhoramentos no desenho e nos implementos tecnológicos, que permitam o pleno reposicionamento da prótese durante o implante (impossível com os dispositivos atuais) e minimizem ou evitem a leve regurgitação aórtica que normalmente se instala após o implante e cujo significado clínico a longo prazo ainda é desconhecido.

Investimentos em treinamento constituem-se em um dos pontos fundamentais do processo. A criação de uma equipe multidisciplinar é altamente recomendável, visto que a associação de clínicos, intervencionistas e cirurgiões auxiliará na adequada seleção dos pacientes e na execução dos procedimentos. Profissionais experientes na interpretação de ecocardiogramas transtorácicos e transesofágicos, angiografias e tomografias também deverão fazer parte do time, visto que uma adequada mensuração dos referenciais anatômicos é imperativa. Além disso, o centro deverá ser treinado e certificado, considerando que todos os cuidados pré, trans e pós-procedimentos são vitais para seu sucesso. Um programa que estabeleça e normatize uma curva de aprendizado progressiva com preceptores capacitados também é indispensável, já que os detalhes e cuidados são muitos e a técnica de implante e manejo de eventuais complicações deve ser muito refinada. Do contrário, todo o eventual e esperado benefício da técnica pode ser perdido.

1 Instituto de Cardiologia do Rio Grande do Sul/Fundação Universitária de Cardiologia - Porto Alegre, RS, Brasil.

Correspondência: Rogério Sarmento-Leite. Av. Princesa Isabel, 395 - Setor de Hemodinâmica - Santana - Porto Alegre, RS, Brasil - CEP 90620-001 E-mail: sarmentoleite@terra.com.br

Recebido em: 17/6/2009 • Aceito em: 18/6/2009 
Mas residem na educação sobre a indicação dos procedimentos e metodologia de seleção dos pacientes os principais pontos a serem desenvolvidos. Não por também englobarem os supracitados, mas por serem os balizadores dos bons e maus resultados e do nicho de indivíduos em que o benefício tem realmente se mostrado consistente. Para tanto, uma cuidadosa avaliação clínica com conhecimento e adequação aos escores de risco é fundamental. Em adição, o estabelecimento de fluxos e normativas para escolha do acesso arterial, tipo de dispositivo, técnica de implante, suporte anestésico, cuidados periprocedimentos e seguimento dos pacientes a curto, médio e longo prazos é indispensável. Em suma, o processo é formado por etapas que não podem ser suplantadas ou negligenciadas e que são as determinantes do sucesso da técnica.

E qual a resposta ao título deste editorial: "Implante valvular aórtico percutâneo: já podemos considerar um procedimento rotineiro e incorporá-lo à prática médica?"? Nos dias atuais, incorporá-lo à prática médica sim! Os resultados até agora apresentados e o corpo de evidências disponíveis têm demonstrado ser uma técnica exequível, segura e eficaz. Considerar um procedimento rotineiro, não! Abstraindo a questão do custo, o implante valvular aórtico percutâneo ainda é reservado a pacientes de alto risco cirúrgico ou àqueles em que a cirurgia não é mais uma opção viável, como bem demonstrado na série apresentada por Hernández-García et al. ${ }^{6}$. Como recomendação final reforça-se a ideia da criação de uma equipe multidisciplinar e integrada, com uma abordagem sistemática da doença para adequada seleção dos pacientes e execução dos procedimentos. É obrigatória rígida atenção aos protocolos e que jamais se ultrapassem etapas no intuito de se atingir os plenos resultados desse procedimento, que consiste em uma técnica bem fundamentada, muito promissora e com enorme potencial, capaz de revolucionar uma das áreas mais delicadas e fascinantes da cardiologia contemporânea.

\section{CONFLITO DE INTERESSES}

Sarmento-Leite recebeu apoio educacional e de pesquisa das empresas Abbot, Biotronik e Cordis; Bureau de Palestrantes das empresas Biotronik e B-Braun; prestou consultoria técnica para Biotronik; e pertence ao Comitê Científico da Scitech.

\section{REFERÊNCIAS BIBLIOGRÁFICAS}

1. Nkomo VT, Gardin JM, Skelton TN, Gottdiener JS, Scott CG, Enriquez-Sarano M. Burden of valvular heart diseases: a population-based study. Lancet. 2006;368(9540):1005-11.

2. Grimberg M, Accorsi TAD. Estenose aórtica no idoso: perspectiva brasileira. Arq Bras Cardiol. 2009;92(2):e36-e39.

3. lung B, Baron G, Butchart EG, Delahaye F, Gohlke-Barwolf C, Levang OW, et al. A prospective survey of patients with valvular heart disease in Europe: the Euro Heart Survey on Valvular Heart Disease. Eur Heart J. 2003;24(13):1231-43.

4. Zajarias A, Cribier AG. Outcomes and safety of percutaneous aortic valve replacement. J Am Coll Cardiol. 2009;53(20): 1829-36.

5. Sarmento-Leite R, Quadros AS, Prates PRL, Zanatta LG, Salgado Filho PA, Grando T, et al. Implante valvular aórtico percutâneo: experiência inicial do Sul do Brasil. Rev Bras Cardiol Invas. 2008;16(4):398-405.

6. Hernández-García JM, Muñoz-García AJ, Alonso-Briales JH, Jiménez-Navarro MF, Domínguez-Franco AJ, Rodríguez-Bailón I, et al. Experiencia inicial de Málaga (España) con la prótesis aórtica CoreValve en el tratamiento de la estenosis aórtica severa sintomática. Rev Bras Cardiol Invas. 2009;17(2): 176-82. 